\title{
Country clustering applied to the water \& sanitation sector: a new tool with potential applications in research \& policy
}

\author{
Kyle Onda, Jonny Crocker, Georgia Lyn Kayser, and Jamie Bartram \\ The Water Institute, Gillings School of Global Public Health, University of North Carolina at \\ Chapel Hill, 148 Rosenau Hall, CB\#7431 Chapel Hill, NC 27599, USA
}

Kyle Onda: konda@live.unc.edu; Jonny Crocker: jonny.crocker@unc.edu; Georgia Lyn Kayser: gkayser@unc.edu

\begin{abstract}
The fields of global health and international development commonly cluster countries by geography and income to target resources and describe progress. For any given sector of interest, a range of relevant indicators can serve as a more appropriate basis for classification. We create a new typology of country clusters specific to the water and sanitation (WatSan) sector based on similarities across multiple WatSan-related indicators. After a literature review and consultation with experts in the WatSan sector, nine indicators were selected. Indicator selection was based on relevance to and suggested influence on national water and sanitation service delivery, and to maximize data availability across as many countries as possible. A hierarchical clustering method and a gap statistic analysis were used to group countries into a natural number of relevant clusters. Two stages of clustering resulted in five clusters, representing 156 countries or 6.75 billion people. The five clusters were not well explained by income or geography, and were unique from existing country clusters used in international development. Analysis of these five clusters revealed that they were more compact and well separated than United Nations and World Bank country clusters. This analysis and resulting country typology suggest that previous geography- or income-based country groupings can be improved upon for applications in the WatSan sector by utilizing globally available WatSan-related indicators. Potential applications include guiding and discussing research, informing policy, improving resource targeting, describing sector progress, and identifying critical knowledge gaps in the WatSan sector.
\end{abstract}

\section{Keywords}

Water and sanitation; cluster analysis; country groupings

\section{Introduction}

Inadequate access to water and sanitation are major causes of millions of deaths and billions of cases of diarrheal and respiratory morbidity each year. This has direct costs to households and health systems, contributing to the poverty trap for billions of people worldwide (PrussUstun and Corvalan, 2006; Waddington and et al., 2009). There is, therefore, a concerted effort to address the lack of basic water and sanitation (WatSan) services worldwide,

(C) 2013 Elsevier GmbH. All rights reserved.

Correspondence to: Jamie Bartram, jbartram@email.unc.edu.

Publisher's Disclaimer: This is a PDF file of an unedited manuscript that has been accepted for publication. As a service to our customers we are providing this early version of the manuscript. The manuscript will undergo copyediting, typesetting, and review of the resulting proof before it is published in its final citable form. Please note that during the production process errors may be discovered which could affect the content, and all legal disclaimers that apply to the journal pertain. 
including initiatives by the World Bank, the UN, and bilateral agencies ("About the Water and Sanitation Program" 2013. United Nations, 2011). Despite these initiatives, there remain 783 million people without access to improved water sources and 2.5 billion people without access to improved sanitation, according to the Joint Monitoring Program (UNICEF and WHO, 2012). Some have suggested that causes of this situation include poorly invested resources, misaligned country investments (Saleth and Dinar, 2000), and other donor failings (Radele and Levine, 2010).

In the WatSan sector, countries are often clustered in order to inform efforts to address the lack of access to WatSan services. Specifically, country clusters are used to explain trends, target investments, and generalize findings. Existing approaches in the WatSan sector for clustering countries have focused on geographic-, economic-, or health-based indicators. Geography-based country clusters group countries based on proximity to each other, while economic- and health-based clusters group countries based on similarity across indicators of country-wide economic performance or health, respectively. The Millennium Development Goals country grouping is geography-based (excepting developed countries, which are put in a separate group) (UNICEF and WHO, 2012). The WHO country grouping is also geography-based, with sub-groupings based on patterns of child and adult mortality ("Definition of region groupings," 2013). The World Bank has three systems for grouping countries: geographic region, income (gross national income per capita), and lending category (determined based on income group and credit rating) ("How we classify countries," 2013)

The WatSan sector is complex; institutional arrangements, levels of service, and program and project experiences do not align by geography, economics, or health alone. The WatSan sector is also impacted by and connected to political, economic, social, and environmental factors. This paper presents a cluster analysis which classifies countries into groups designed to be representative of WatSan sector arrangements, performance, and progress.

\section{Background}

\section{Previous Applications of Cluster Analysis}

Cluster analysis denotes a family of methods in applied statistics used to identify groups in data, where the groups are formed to be as homogenous as possible, while maximizing the differences between groups (Kaufman and Rousseeuw, 1990). Cluster analysis has been applied across a wide range of disciplines, including chemistry, genetics, and marketing to create interpretable classifications using multiple variables (Downs and Barnard, 2003; Eisen et al., 1998; Zandpour and Harich, 1996). Cluster analysis has been used to group countries along national-level indicators in political economy and international business contexts (Ketchen and Shook, 1996; Wolfson et al., 2004). In the international development sector, previous work has shown that applying cluster analysis to countries over a broad set of relevant economic indicators can yield more informative country classifications than can traditional geographic- and income-based demarcations (Berlage and Terweduwe, 1988). Cluster analysis has also been used to group countries across multiple dimensions of environmental sustainability (Esty, 2002).

\section{Major Approaches in Cluster Analysis}

There are many methods of cluster analysis, of which Everitt et al., 2001 offers an overview. Major clustering approaches include hierarchical, optimization, and model-based methods. Hierarchical methods connect data points based on a measure of distance between the data points to form clusters. Such methods produce a hierarchy of clusters that can be judged to merge together as a distance threshold increases, and can be expressed visually as a 
dendrogram. Optimization methods produce a partition of the data into a number of groups $k$ that must be pre-specified by the analyst, by choosing $k$ data points as pre-assigned "cluster centers," and then assigning data points to those centers in a way that minimizes the squared distances between members within that cluster. Model-based methods generally use an expectation-maximization algorithm that assigns data points to a fixed number of Gaussian distributions.

An important limitation to any of these methods is that there is no internal mechanism to distinguish between important and unimportant indicators. As such, the resulting clusters are sensitive to the indicators included in the analysis; therefore, indicators must be chosen carefully based on conceptual underpinnings highly dependent on sector context.

\section{Methods Data Sources}

After a literature review and consultation with experts (academics and practitioners) in the WatSan sector, we chose indicators with which to cluster countries based on their relevance and suggested influence on national water and sanitation service delivery, as well as data availability so as to capture a majority of the world's population in the country groupings. ${ }^{1}$ Suggested influence here means that the indicator has a hypothesized mechanism by which it influences the level of water and sanitation service delivery, or has been associated with levels of service delivery in previous studies. Previously cited influences on access to water and sanitation service and the quality of that service provided include: investment, aid, governance, education, human capital, inequality and water availability (Fry, 2008). Table 1 presents the indicators we chose for the cluster analysis, and the rationale for their inclusion. Seven of the indicators were chosen for their influence on the WatSan sector's capacity and arrangements and two indicators were chosen for representing levels of WatSan service delivery.

There are many other indicators for which data is available and also may have influence on national water and sanitation service delivery. Such indicators were excluded either because of missing data for many countries and a relatively large proportion of the global population, or to avoid co-linearity which would distort the results of the cluster algorithm. Examples of indicators excluded due to data availability are domestic water and sanitation infrastructure investment and bacteriological water quality. National figures for domestic public and private investment in water and sanitation infrastructure are available from a limited number of national government expenditure reports, as well as from 26 public expenditure reviews conducted by the World Bank (Meegham and van der Berg, 2012). Nationally representative drinking water quality data is only available for the five countries covered by the Rapid Assessment of Drinking Water Quality project of WHO and UNICEF (Onda et al. 2012). We avoided constructed indices such as the human development index (HDI) and water poverty index (WPI) in order to focus on the underlying data and to avoid unnecessary colinearity among these indices and chosen indicators, many of which are constituents of such indices (Anand and Sen, 1994; Sullivan, 2002). We did not include the health indicator under-five diarrheal incidence because the available figures were produced using a regression that included WHO region and per capita national income as covariates (Walker et al., 2012). We included years of education completed over other education indicators because we deemed it to be relevant for a range of WatSan arrangements and outcomes.

\footnotetext{
${ }^{1}$ The consulted experts included: faculty in Environmental Engineering at the University of North Carolina, the University of Cape Town, Bristol University, senior water and sanitation experts at WHO and a Political Economy research consultant at the World Bank.
} 


\section{Clustering Method}

A cluster analysis was conducted to classify countries into groups based on similarity across the nine selected WatSan indicators. We used a hierarchical clustering method to allow for the natural number of relevant clusters to emerge, since optimization- or model-based approaches involve pre-determining the number or shape of clusters. All computations were performed with $\mathrm{R}$ version 2.15.1 (R Core Team, 2012).

We elected to use the squared Euclidean distance as the distance metric, which is the square of the simple geometric distance in multidimensional space (Kaufman and Rousseeuw, 1990). This requires that all indicator variables be on the same scale in order for each variable to be given equal weighting in the overall distance calculation.

We elected to use the raw variables rather than to use a data reduction technique such as principal components analysis because the use of such synthetic variables in cluster analysis is generally considered poor practice (Kettenring, 2006). Highly right-skewed variables were transformed by taking the natural logarithm. Highly left-skewed variables were reflected, transformed by the natural logarithm, and reflected back to preserve the original rank-order. Then, all variables were standardized to a mean of 0 and standard deviation of 1 , and the distance matrix for all country pairs was calculated. We used Ward's agglomerative clustering algorithm, which at each step combines clusters so as to minimize the resulting within-cluster variance (Kaufman and Rousseeuw, 1990).

The number of clusters into which to divide the resulting dendrogram was determined as the number of clusters corresponding to the first local maximum of the gap statistic. The gap statistic is a measure of the difference between the within-cluster dispersion (sum-of-squares around the cluster means), and the expected value of this dispersion over a null reference distribution for a given number of clusters. The magnitude of the gap statistic represents the degree to which the proposed clusters are internally homogenous and well separated. The first local maximum (subject to a confidence- interval check) of the gap statistic represents the point at which further joining of clusters would require combining clusters that are significantly separated relative to the previous combination (Tibshirani et al., 2001).

We internally validated the resulting clusters by calculating the Dunn and Davies-Bouldin Indices, which are both measures of the degree to which a clustering is compact and well separated (Davies and Bouldin, 1979; Dunn, 1973). These indices were also calculated for the World Bank, MDG, and WHO groupings to evaluate whether our analysis produced a superior clustering.

\section{Data analysis}

We included 156 countries, representing 6.75 billion people, in our dataset. We excluded 40 countries, representing 99.7 million people, from an initial dataset of 196, due to missing data. The most common missing values were the Gini index, water availability, and GDP per capita; missing from 30, 25, and 16 countries, respectively. These countries and their populations are shown in Table 2. The GDP, freshwater availability, and ODA indicators were highly positively skewed, and were log- transformed accordingly. The water and sanitation access indicators were highly negatively skewed, and were reflected, logtransformed, and reflected again. We utilized the gap statistic to cluster countries. The first attempt resulted in a clustering for which the gap statistic yielded only two clusters, one with 33 countries characterized by high incomes and governance effectiveness, no aid inflow, and near-universal water and sanitation access that generally corresponded to the World Bank's High-income OECD grouping, plus such wealthy small countries as Singapore and Malta. We elected to remove this group as its own cluster, and perform another cluster analysis on the remaining 124 countries in order to take advantage of the country variability that was 
otherwise overwhelmed by the difference between these wealthier countries and the rest of the world.

\section{Results}

A gap statistic analysis resulted first in two distinct groups, with the first being composed of countries typically considered developed or newly industrialized. The second analysis of the second group resulted in four country clusters. Greater subdivision would have resulted in clusters that were statistically similar, while greater aggregation would have resulted in highly internally heterogeneous clusters. The dendrogram resulting from this cluster analysis is shown in Figure 1, and the corresponding gap curve yielding four clusters is shown in Figure 2. Table 3 shows the resulting five water and sanitation country clusters. Figure 3 shows the cluster country membership on a world map. The cluster indicator variable means are summarized in Table 4. The Dunn and Davies-Bouldin Indices for our clusters, as well as the World Bank, WHO, and MDG groupings are shown in Table 5. Our clusters have both the largest Dunn index and smallest Davies-Bouldin index, indicating that they represent a superior grouping along the chosen relevant indicators.

Cluster 1 consists of 33 developed and recently industrialized countries from North America, Europe, and the wealthier Asian countries. Cluster 1 countries are characterized by the highest GDPs per capita and GE scores, relatively low levels of inequality as measured by the Gini index, the highest expected years of education, high urbanization, and nearuniversal water and sanitation access. Example members are Canada, Germany, and Japan.

Cluster 2 consists of 15 geographically disparate countries. Cluster 2 countries are characterized by the second-highest GDPs per capita, second-highest GE scores, and second-highest expected years of education. They are urbanized to the same degree as Cluster 1 countries. They also have very high, though not quite universal water and sanitation access, and receive the lowest amount of WatSan ODA of the groups that receive such aid. Example members are Argentina, Russia, and Iran.

Cluster 3 consists of 28 mostly eastern European and Middle Eastern countries, as well as some Latin American and Asian countries. Cluster 3 countries are middle-income, have moderate expected years of education, are roughly $50 \%$ urban, and have similar water and sanitation access to countries in Cluster 2. Cluster 3 countries stand out as having the lowest renewable freshwater resources per capita, and the highest WatSan ODA per capita of all the clusters. Example members are Algeria, Armenia, El Salvador, and Sri Lanka.

Cluster 4 consists of 24 countries mostly from Latin American and Southern African, and some Asian countries. Cluster 4 countries are characterized by similar GDP per capita, expected years of education, urbanization, and water access to those in Cluster 3, though half the ODA. Cluster 4 countries have higher income inequality, lower sanitation access, and more renewable freshwater resources than Cluster 3. Example members are Honduras, South Africa, and the Philippines.

Cluster 5 consists of 51 Sub-Saharan African and South/South-East Asian countries plus Haiti. Approximately $75 \%$ of cluster 5 countries are from Africa. Cluster 5 countries are characterized by the lowest GDP per capita, GE scores, expected years of education, urbanization, and water and sanitation access of all clusters; as well as relatively high WatSan ODA and renewable freshwater resources. Example members are Cambodia, Mozambique, and Pakistan.

The 40 countries representing 99.7 million people which were excluded for missing data are primarily small island states or fragile states. However, they should not be treated as a sixth 
cluster, as, despite some similarities, they were not grouped using the clustering algorithm. Example countries are the Bahamas, Serbia, and Somalia.

\section{Discussion}

Our novel application of cluster analysis to the WatSan sector classifies countries into groups designed to be representative of WatSan sector arrangements, performance, and progress. The Dunn and Davies-Bouldin cluster indices shown in Table 5 indicate that these comparative country clusters are more compact and well-separated across nine WatSanrelated variables indicators than are the geography based MDG and WHO country clusters, and the World Bank income based country clusters. These WatSan clusters demonstrate that, for example, El Salvador, Georgia, and Egypt (Cluster 3); and Afghanistan, Laos, and Uganda (Cluster 5) are more similar along the WatSan indicators selected than Cambodia, Vietnam, and Thailand (each in a different cluster, though in the same geographic region) or South Africa, Algeria, and Chad (also in different clusters though within the same region). MDG, WHO, World Bank, and other existing country groupings have been used by others for three major applications which could be improved upon in the WatSan sector by using our country clustering model: (1) research, (2) investments and policy, and (3) discussing and communicating progress.

Use of existing country groupings in research has included stratified sampling of countries for multi-country studies, discussing findings (Fry, 2008), and extrapolating study outcomes across countries (Hutton, 2012; Walker et al., 2012). Clustering countries along critical WatSan indicators could improve these specific research applications in the WatSan sector. For example, our country clusters could be useful for stratified sampling. When the goal of stratified sampling is to better characterize or account for the variability or breadth of WatSan practices and outcomes, rather than selecting a country from each region, one could select a country from each of our clusters, which would have a higher likelihood of representing a range of WatSan practices. The clusters generated for this paper could also be used to extrapolate data sets to countries with data gaps. Many studies in water quality, water consumption, and water system sustainability exist for small sets of countries. These small data sets are not always generalizable across existing country groupings. For datasets inclusive of enough countries to show low variance within clusters, data could be extrapolated across our country groupings.

Geographic country groupings have been used to target concessional lending (The World Bank, n.d.), and to guide investment and development strategies (Sachs, 2005). WatSan specific needs do not inherently correlate with geography, but logically relate to the nine indicators used to cluster countries in this study. WatSan-specific investments and strategies may be better aligned with need if the country clusters presented in this table were utilized.

The most commonly referenced WatSan global database is the JMP data on water and sanitation access. The 2012 JMP report summarizes water and sanitation progress using the MDG regional groupings: Oceania, Southern Asia, Eastern Asia, South-Eastern Asia, Caucasus and Central Asia, Western Asia, Sub-Saharan Africa, Northern Africa, Latin America and the Caribbean, and Developed Regions. These eleven regions are frequently used to discuss and generate debate on levels of water and sanitation access and progress trends (UNICEF and WHO, 2012; Pruss-Ustun and Corvalan, 2006; United Nations, 2011). Our cluster analysis shows that some members from these regional groups are quite unique from their geographic neighbors. Our country clustering could be used alongside geographic groupings to compare water and sanitation progress and generate debate on progress and trends in the WatSan sector. 
There are several limitations to this study. The proposed clusters should not be thought of as definitive, as they are highly dependent on the variables indicators chosen, and indeed, the years of the data included. Changes in the figures from year to year would necessarily change cluster membership. It would be expected that countries undergoing significant changes along the chosen indicators would change cluster membership. Changes in variable indicator choice, chosen distance metric, clustering algorithm, or cluster number decision metric would all change the results.

Further research on the WatSan country cluster typology could involve cluster validation, or creating targeted clusters for specific regional or sub-national applications. Cluster validation could be done by selecting a non-JMP WatSan indicator to check for similarity within clusters and difference between clusters if and when they become available. Application of cluster analysis where policies and strategies demand a regional or subnational focus could be done by applying the clustering approach to the member states of relevant regional political groupings such as the African Ministers' Council on Water (AMCOW). Creating clusters within groups such as AMCOW would be superior for applications such as organizing regional conferences, or building human resource capacity.

\section{Conclusion}

Clustering countries along relevant WatSan indicators produces a comparative country typology that is more relevant to the WatSan sector than country groupings that are currently utilized throughout the sector. WatSan indicators included in our cluster analysis were based on their influence on national water and sanitation service delivery. These WatSan clusters push beyond geographic country groupings to suggest that country-level WatSan outcomes can be accounted for and compared across factors that are more relevant than geography or income alone, the two most commonly used methods of stratification in the international development field. This WatSan country typology could help the sector to better propose policies, track progress, target funds, and plan research in ways that account for country similarities and differences across the major outcome drivers in the sector.

\section{Acknowledgments}

Funding for this study was provided by the National Institute of Health, Water Wisdom (Bentley, PI), the Aquatest Research Consortium (University of Bristol, UK), and the International Association of Plumbing and Mechanical Officials (IAPMO). The conclusions reported are those of the authors and do not necessarily reflect the views of the funding organizations.

\section{References}

About the Water and Sanitation Program [WWW Document]. WSP; 2013. URL http://www.wsp.org/ wsp/about

Anand, S.; Sen, AK. Human Development Occasional Papers 19922007. 1994. Human development Index: Methodology and Measurement; p. 370

Bakker K, Kooy M, Shofiani NE, Martijn EJ. Governance Failure: Rethinking the Institutional Dimensions of Urban Water Supply to Poor Households. World Dev. 2008; 36:1891-1915.

Berlage L, Terweduwe D. The classification of countries by cluster and by factor analysis. World Dev. 1988; 16:1527-1545.

Clemens M, Kenny C, Moss T. The Trouble with the MDGs: Confronting Expectations of Aid and Development Success. World Dev. 2007; 35:735-751.

Data resources and estimates of the WHO/UNICEF Joint Monitoring Programme for Water Supply and Sanitation [WWW Document]. 2012. URL http://www.wssinfo.org/data-estimates/introduction

Davies DL, Bouldin DW. A Cluster Separation Measure. IEEE Transactions on Pattern Analysis and Machine Intelligence. 1979; 1:224-227. [PubMed: 21868852] 
Definition of region groupings [WWW Document]. WHO; 2013. URL http://www.who.int/healthinfo/ global_burden_disease/definition_regions/en/index.html

Downs GM, Barnard JM. Clustering methods and their uses in computational chemistry. Rev Comput Chem. 2003; 18:1-40.

Dunn JC. A Fuzzy Relative of the ISODATA Process and Its Use in Detecting Compact WellSeparated Clusters. Cybernetics and Systems. 1973; 3:32-57.

Education for All Global Monitoring Report. UNESCO; Paris: 2011.

Eisen MB, Spellman PT, Brown PO, Botstein D. Cluster analysis and display of genome-wide expression patterns. Proc Nat Acad Sci. 1998; 95:14863-14868. [PubMed: 9843981]

Esty, D. Environmental Sustainability Index. Yale Center for Environmental Law and Policy; New Haven: 2002.

Everitt, BS.; Landau, S.; Leese, M. Cluster Analysis. Arnold; London: 2001.

Fry LM. Water and non-water related challenges of achieving global sanitation coverage. Environ Sci Technol. 2008; 42:4298-4304. [PubMed: 18605547]

Gomanee K, Morrissey O, Mosley P, Verschoor A. Aid, Government Expenditure, and Aggregate Welfare. World Dev. 2005; 33:355-370.

How we classify countries [WWW Document]. World Bank; 2013. URL http://data.worldbank.org/ about/country-classifications

Hutton, G. Global Costs and Benefits of Drinking-Water Supply and Sanitation Interventions to Reach the MDG Target and Universal Coverage [WWW Document]. 2012.

Jalan J, Somanathan E, Chaudhuri S. Awareness and the demand for environmental quality: survey evidence on drinking water in urban India. Environ Dev Econ. 2009; 14:1-28.

Kaufman, L.; Rousseeuw, P. Finding groups in data: An introduction to cluster analysis. Wiley; New York: 1990.

Ketchen D, Shook C. The application of cluster analysis in strategic management research: an analysis and critique. Strategic Manage J. 1996; 17:441-458.

Kettenring JR. The practise of cluster analysis. J Classification. 2006; 23:3-30.

Manghee, S.; van der Berg, C. Guidance Note: Public Expenditure Review from the Perspective of the Water and Sanitation Sector. World Bank; 2012. URL http://water.worldbank.org/sites/ water.worldbank.org/files/publication/Water-Guidance-Note-PER.pdf

Meeting the Water Governance Challenge. Meeting the Reform Challenge; OECD Publishing; 2012.

Monteiro CA, Benicio MHD, Conde WL, Konno S, Lovadino AL, Barros AJD, Victora CG. Narrowing socioeconomic inequality in child stunting: the Brazilian experience, 1974-2007. Bull World Health Organ. 2010; 88:305-311. [PubMed: 20431795]

Nunan F, Satterthwaite D. The influence of governance on the provision of urban environmental infrastructure and services for low-income groups. Int Planning Stud. 2001; 6:409-426.

Onda K, LoBuglio J, Bartram J. Global access to safe water: accounting for water quality and the resulting impact on MDG progress. Int J Env Res Public Health. 2012; 9:880-894. [PubMed: 22690170]

Pruss-Ustun, A.; Corvalan, C. Towards an estimate of the environmental burden of disease. World Health Organization; Geneva: 2006. Preventing disease through healthy environments.

[accessed 6.1.12] Query Wizard for International Development Statistics [WWW Document]. 2011. URL http://stats.oecd.org/qwids/

R Core Team. R: A Language and Environment for Statistical Computing. 2012.

Radele, S.; Levine, R. Can we build a better mousetrap? Three new institutions designed to improve aid effectiveness. In: Easterly, W., editor. Reinventing Foreign Aid. EBSCO; 2010. p. 431-460.

Rogers AF, et al. Characteristics of latrine promotion participants and non-participants and nonparticipants; inspection of latrines; and perceptions of household latrines in Northern Ghana. Tropical Medicine and International Health. 2007; 12:772-782. [PubMed: 17550475]

Rogers, BP.; Hall, AW. Water. 2003. Effective Water Governance; p. 36

Rudra N. Openness and the Politics of Potable Water. Comp Political Stud. 2011; 44:771-803. 
Sachs, JD. United Nations Millenium Project. 2005. Investing in Development: A Practical Plan to Achieve the Millenium Development Goals [WWW Document].

Saleth RM, Dinar A. Institutional changes in global water sector: trends. Water Policy. 2000; 2:175199.

Shafik N. Economic development and environmental quality: an econometric analysis. Oxford Economic Papers. 1994; 46:757-773.

Sullivan C. Calculating a Water Poverty Index. World Dev. 2002; 30:1195-1210.

The World Bank. A History of Operational Guidelines [WWW Document]. n.d. URL http:// data.worldbank.org/about/country-classifications/a-short-history

Tibshirani R, Walther G, Hastie T. Estimating the number of clusters in a data set via the gap statistic. J R Stat Soc - Series B: Stat Methodology. 2001; 63:411-423.

UNICEF, WHO. Progress on drinking water and sanitation. 2012. 2012 Update

United Nations. [accessed 11.30.11] Goal 7: Ensure environmental sustainability [WWW Document]. 2011. URL http://www.un.org/millenniumgoals/environ.shtml

Waddington, et al. Water, sanitation, and hygiene interventions to combat childhood diarrhea in developing countries. Int Initiative for Impact Eval. 2009

Wagstaff A. Poverty and health sector inequalities. Bull World Health Organ. 2002; 80:97-105. [PubMed: 11953787]

Walker CLF, Aryee MJ, Boschi-Pinto C, Black RE. Estimating diarrhea mortality among young children in low and middle income countries. PloS one. 2012; 7:e29151. [PubMed: 22235266]

Wolf S. Water and sanitation for all? Rural versus urban provision. Int J Services, Econ, and Manage. 2009; 1:358-370.

Wolfson M, Madjd-Sadjadi Z, James P. Identifying national types: A cluster analysis for politics, economics, and conflict. J Peace Res. 2004; 41:607-623.

[accessed 6.1.12] World Development Indicators [WWW Document]. 2013. URL http:// data.worldbank.org/data-catalog/world-development-indicators

World Urbanization Prospects, the 2011 Revision. United Nations; New York: 2011.

Worldwide Governance Indicators [WWW Document]. 2011. URL http://data.worldbank.org/datacatalog/world-development-indicators

Zandpour F, Harich KR. Think and feel country clusters: A new approach to international advertising. Int J Advertising. 1996; 15:325-344. 


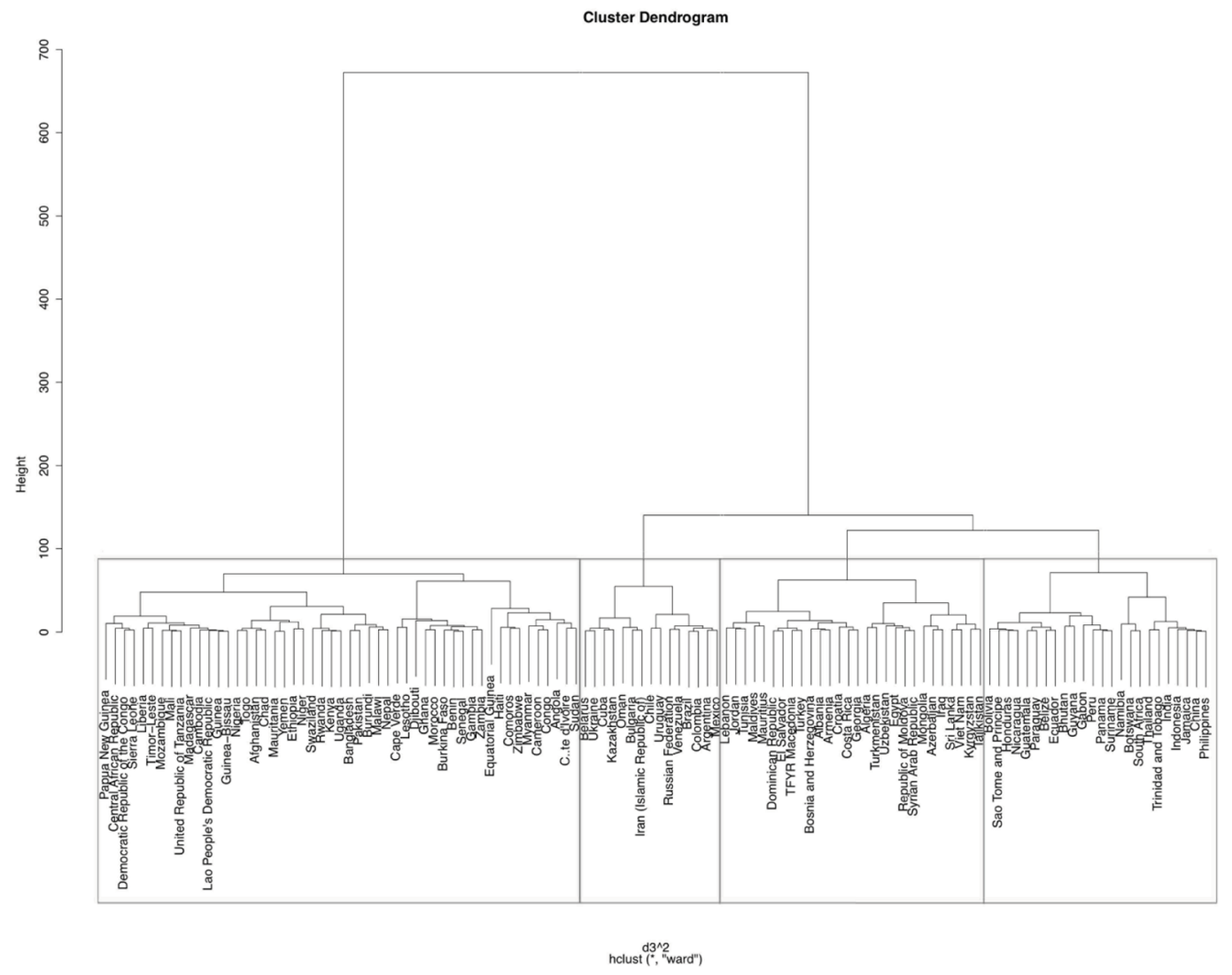

Figure 1.

Dendrogram of Agglomerative Clustering of Countries Along WASH Indicators. 


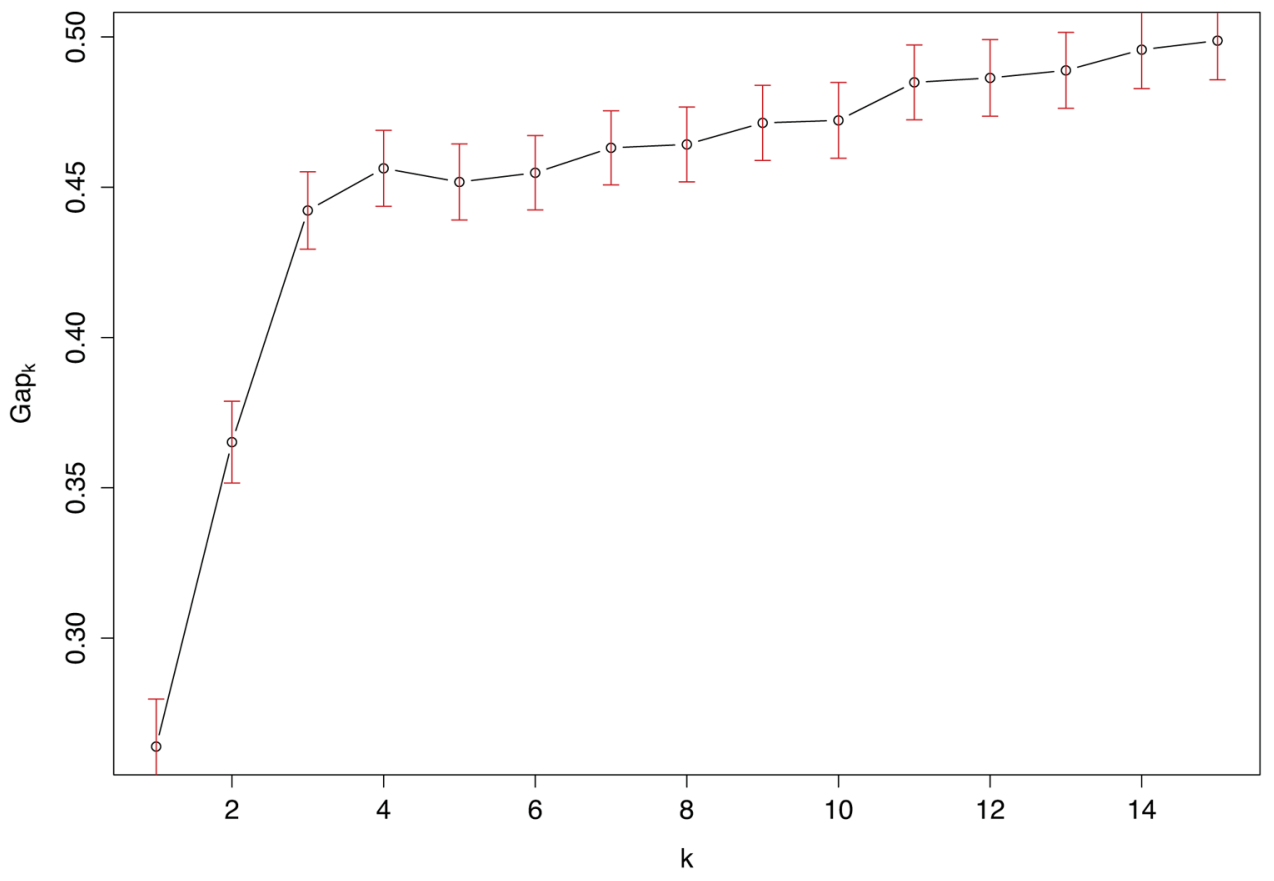

Figure 2.

Gap statistic by number of clusters (k) for Country-Level WASH Indicator Data 


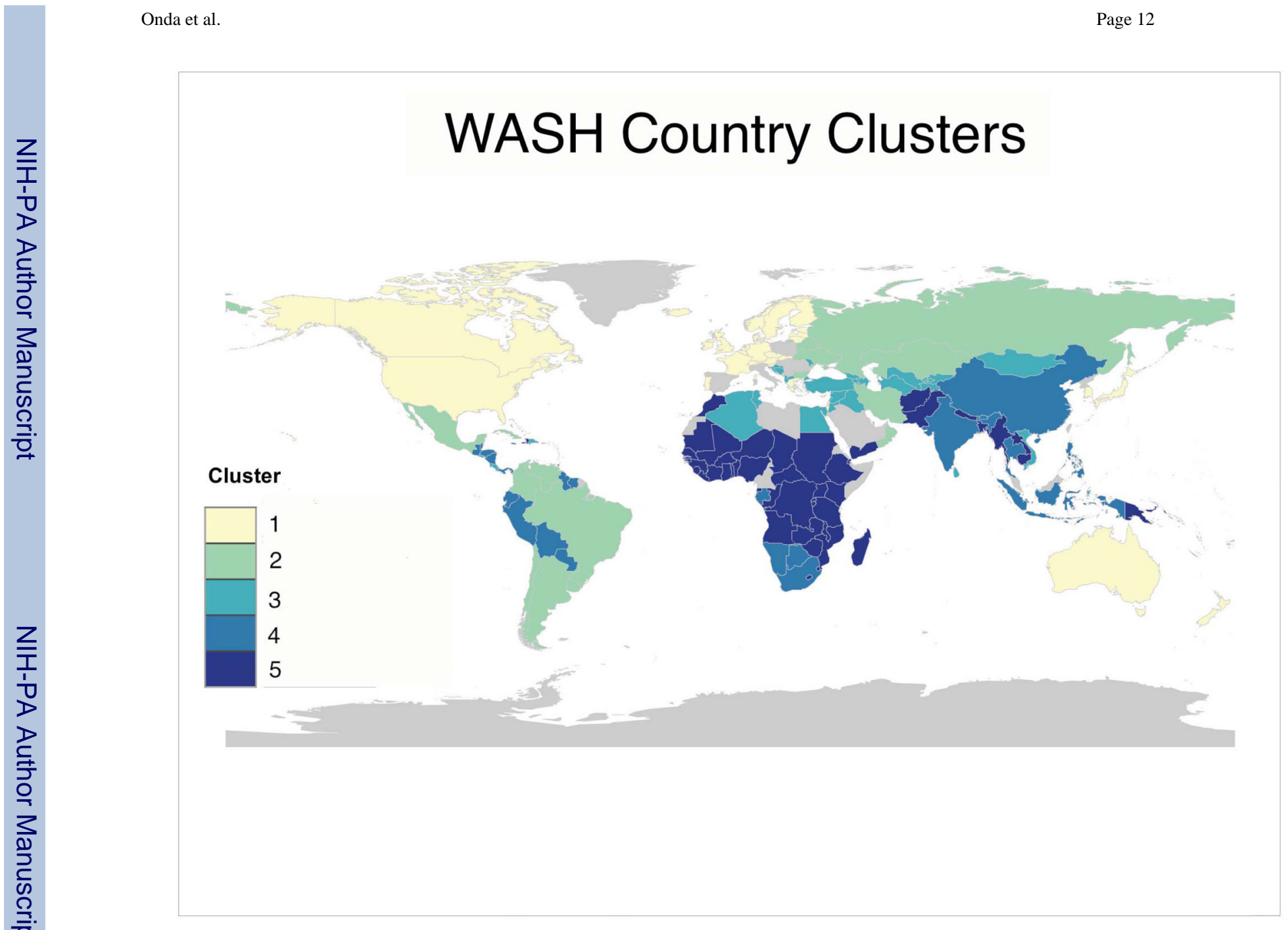

Figure 3.

Geographic distribution of WASH country clusters. 


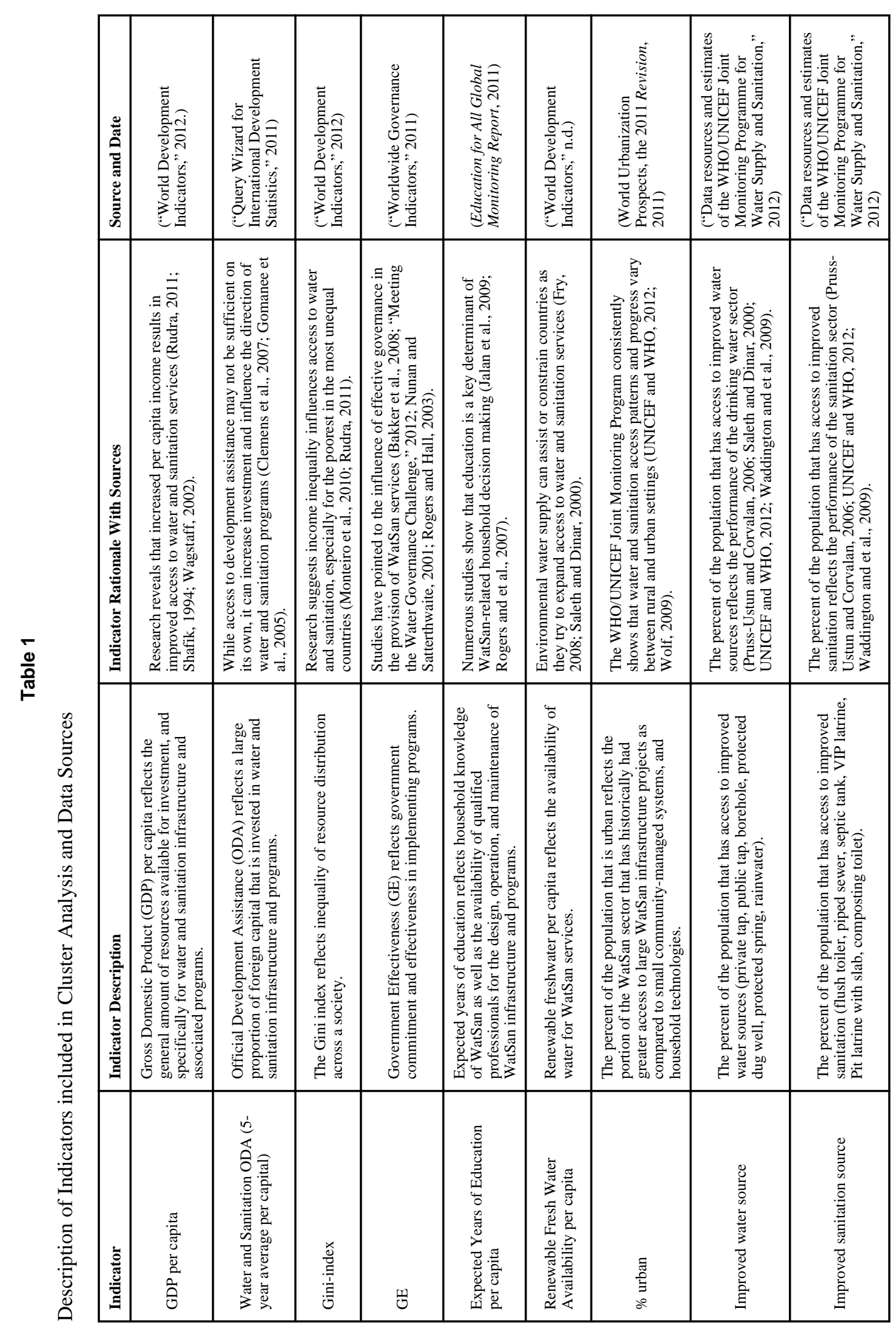


Table 2

Countries with population (millions) excluded due to missing data

\begin{tabular}{lrlr}
\hline Andorra & 0.09 & Monaco & 0.04 \\
Antigua and Barbuda & 0.09 & Montenegro & 0.63 \\
Aruba & 0.11 & Northern Mariana Islands & 0.06 \\
Bahamas & 0.34 & Occupied Palestinian Territory & 4.04 \\
Bahrain & 1.26 & Palau & 0.02 \\
Barbados & 0.27 & Puerto Rico & 3.75 \\
Brunei Darussalam & 0.40 & Saint Kitts and Nevis & 0.05 \\
Cayman Islands & 0.06 & Saint Lucia & 0.17 \\
DPR Korea & 9.93 & Saint Vincent and the Grenadines & 0.11 \\
Dominica & 0.07 & Samoa & 0.18 \\
Eritrea & 5.25 & San Marino & 0.03 \\
Fiji & 0.86 & Saudi Arabia & 27.45 \\
French Polynesia & 0.27 & Serbia & 9.86 \\
Grenada & 0.10 & Seychelles & 0.09 \\
Guam & 0.18 & Solomon Islands & 0.54 \\
Kiribati & 0.10 & Somalia & 9.33 \\
Kuwait & 2.74 & Tonga & 0.10 \\
Libya & 3.99 & Turks and Caicos Islands & 0.04 \\
Marshall Islands & 0.05 & Tuvalu & 0.01 \\
Micronesia (Federated States of) & 0.11 & Vanuatu & 0.24 \\
\hline Total & & 99.7 &
\end{tabular}


Table 3

Water and sanitation sector country clusters

\begin{tabular}{|c|c|}
\hline Cluster & Country Members \\
\hline $1(n=33)$ & $\begin{array}{l}\text { Australia, Austria, Belgium, Canada, Cyprus, Czech Republic, Denmark, Estonia, Finland, France, Germany, Greece, Iceland, } \\
\text { Ireland, Israel, Japan, Latvia, Lithuania, Luxembourg, Malta, Netherlands, New Zealand, Norway, Portugal, Singapore, Slovak } \\
\text { Republic, Slovenia, South Korea, Spain, Sweden, Switzerland, United Kingdom, United States }\end{array}$ \\
\hline $2(n=15)$ & $\begin{array}{l}\text { Argentina, Belarus, Brazil, Bulgaria, Chile, Colombia, Cuba, Iran, Kazakhstan, Mexico, Oman, Russia, Ukraine, Uruguay, } \\
\text { Venezuela }\end{array}$ \\
\hline $3(n=28)$ & $\begin{array}{l}\text { Albania, Algeria, Armenia, Azerbaijan, Bosnia and Herzegovina, Costa Rica, Croatia, Dominican Republic, Egypt, El Salvador, } \\
\text { FYR Macedonia, Georgia, Iraq, Jordan, Kyrgyzstan, Lebanon, Maldives, Mauritius, Moldova, Mongolia, Sri Lanka, Syria, } \\
\text { Tajikistan, Tunisia, Turkey, Turkmenistan, Uzbekistan, Vietnam }\end{array}$ \\
\hline $4(n=24)$ & $\begin{array}{l}\text { Belize, Bhutan, Bolivia, Botswana, China, Ecuador, Gabon, Guatemala, Guyana, Honduras, India, Indonesia, Jamaica, Namibia, } \\
\text { Nicaragua, Panama, Paraguay, Peru, Philippines, Sao Tome and Principe, South Africa, Suriname, Thailand, Trinidad and Tobago }\end{array}$ \\
\hline $5(\mathrm{n}=51)$ & $\begin{array}{l}\text { Afghanistan, Angola, Bangladesh, Benin, Burkina Faso, Burundi, Cambodia, Cape Verde, Central African Republic, Chad, } \\
\text { Comoros, Congo, Cote d'Ivoire, Democratic Republic of the Congo, Djibouti, Equatorial Guinea, Ethiopia, The Gambia, Ghana, } \\
\text { Guinea, Guinea-Bissau, Haiti, Kenya, Laos, Lesotho, Liberia, Madagascar, Malawi, Mali, Mauritania, Morocco, Mozambique, } \\
\text { Myanmar, Nepal, Niger, Nigeria, Pakistan, Papua New Guinea, Rwanda, Senegal, Sierra Leone, Sudan, Swaziland, Tanzania, } \\
\text { Timor-Leste, Togo, Uganda, Yemen, Zambia, Zimbabwe }\end{array}$ \\
\hline
\end{tabular}


Table 5

Internal Cluster Validation Indices.

\begin{tabular}{lcc} 
Grouping & Dunn & Davies-Bouldin \\
\hline WatSan Clusters & 1.04 & 1.57 \\
World Bank Income Groups & 1.02 & 1.64 \\
WHO Regions & 0.84 & 1.84 \\
MDG Regions & 0.78 & 1.87 \\
\hline \multirow{2}{*}{ Higher values indicate a better clustering } \\
** \\
Lower values indicate a better clustering
\end{tabular}

